\title{
Pengaruh Influencer Marketing Tiktok terhadap Brand Image Bittersweet by Najla
}

\author{
Winnie Agustina, Wulan Purnama Sari \\ winnieagustina99@gmail.com,wulanp@fikom.untar.ac.id \\ Fakultas Ilmu Komunikasi Universitas Tarumanagara
}

\begin{abstract}
As the digital world develops, various application platforms have emerged that make technological sophistication even more perfect, namely Tiktok. This platform can be used as a means of doing business by taking advantage of the various features that can attract buyers. Najla Bisyir as Owner of Bittersweet by Najla uses the right influencers to do marketing through Tiktok to enhance the image of the product. The purpose of this research was to see the effect of tiktok marketing on the Bittersweet brand image by Najla. This research uses several theories, namely, influencer marketing, brand image, and social media. The research approach was carried out quantitatively with a survey method. The population of followers / followers of Bittersweet by Najla through the Tiktok platform and a sample size of 100 respondents determined by simple random sampling. The results of this study indicate that influencer marketing affects the brand image of being bitter by Najla through the Tiktok platform so that consumer confidence in the product increases. The number of followers of Bittersweet by Najla through the Tiktok platform is dominated by generation $Z$ and female, so this factor can have an influence in consuming these ads. For academics who are interested in researching the factors affecting brand image, it is advisable to add other factors that will be studied and the object of research chosen is more general.
\end{abstract}

Keyword: brand image, influencer, marketing, tiktok

\begin{abstract}
Abstrak
Tiktok adalah aplikasi yang kini tengah disukai oleh kaum milenial. Platform ini dapat digunakan sebagai sarana untuk berbisnis dengan memanfaatkan keunggulan dari berbagai fitur yang dapat menarik pembeli. Najla Bisyir selaku Owner Bittersweet by Najla menggunakan influencer yang tepat dalam melakukan pemasaran melalui Tiktok untuk membangung citra produk tersebut. Tujuan penelitian adalah mengetahui pengaruh influencer marketing Tiktok terhadap brand image Bittersweet by Najla. Penelitian menggunakan beberapa teori yaitu, influencer marketing, brand image, dan media sosial. Pendekatan penelitian dilakukan secara kuantitatif dengan metode survei. Populasi penelitian merupakan pengikut followers dari Bittersweet by Najla melalui platform Tiktok dan jumlah sampel sebanyak 100 responden yang ditentukan secara simple random sampling. Hasil penelitian ini menunjukkan bahwa influencer marketing memengaruhi brand image terhadap Bittersweet by Najla melalui platform Tiktok sehingga kepercayaan konsumen terhadap produk meningkat. Jumlah pengikut Bittersweet by Najla melalui platform Tiktok didominasi oleh kaum generasi $\mathrm{Z}$ dan berjenis kelamin perempuan sehingga faktor ini dapat memberikan pengaruh dalam mengonsumsi iklan tersebut. Bagi para akademisi yang tertarik meneliti tentang faktor yang mempengaruhi brand image, disarankan untuk menambahkan faktor lain yang akan diteliti dan objek penelitian yang dipilih lebih umum.
\end{abstract}

Kata Kunci: citra merek, influencer, pemasaran, tiktok 
Winnie Agustina, Wulan Purnama Sari: Pengaruh Influencer Marketing Tiktok terhadap Brand Image Bittersweet by Najla

\section{Pendahuluan}

Tiktok adalah aplikasi media sosial yang menyediakan dukungan pembuatan video yang dilengkapi dengan fitur-fitur yang menarik. Tiktok telah diunduh sebanyak 2 miliar kali melalui Google Play Store dan Apple App Store berdasarkan data dari Sensor Tower per April 2020. Jumlah ini sudah termasuk Douyin, saudara Tiktok yang khusus untuk pasar China. Hal ini merupakan sebuah rekor baru yang diperoleh Tiktok dalam lima bulan setelah meraih 1,5 miliar unduhan. Atas pencapaian ini, Tiktok menjadi aplikasi pertama setelah aplikasi keluarga Facebook (WhatsApp, Instagram, dan Messenger) yang memecahkan rekor 2 miliar unduhan sejak 1 Januari 2014. Tidak hanya itu, Tiktok sekaligus menjadi platform yang paling banyak diunduh di seluruh dunia per Juli 2020.

Berdasarkan laporan data AppAnnie, pengguna aktif platform Tiktok hingga Juli 2020 sudah mencapai 689.174.299 juta user secara global dan akan semakin besar jumlahnya. Artinya, terlihat bahwa ada target konsumen pada platform ini sekaligus merupakan kesempatan yang besar bagi pebisnis untuk memanfaatkan Tiktok sebagai media promosi produknya. Peluang ini dimanfaatkan oleh Owner Bittersweet by Najla, Najla Bisyir adalah salah satu UKM yang berani mencoba cara baru, yakni beriklan di platform Tiktok. Najla telah merintis usahanya dari tahun 2017 khususnya dalam menjual Dessert Box dengan berbagai varian rasa yang unik. Hingga saat ini pun telah membuka sistem reseller hampir di seluruh pulau Makassar, Palembang, Lampung, dan Jawa dengan jumlah lebih dari 40 gerai.

Pandemi Covid 19 tentunya memberikan dampak bagi kelangsungan Usaha Mikro, Kecil dan Menengah (UMKM) di Indonesia. Berdasarkan data dari Kementrian Koperasi dan UKM terdapat sekitar 37.000 UMKM yang memberikan laporan terkena dampak diantaranya, 56\% terjadi penurunan penjualan, $22 \%$ terdapat masalah pada aspek pembiayaan, 15\% masalah pada distribusi barang, dan 4\% terdapat kesulitan mendapatkan bahan baku mentah. Namun, Najla Bisyir selaku Owner Bittersweet by Najla menjelaskan bahwa platform Tiktok membantu usahanya dalam menghadapi tantangan dalam pandemi ini, yaitu penurunan angka pejualan. Didukung dengan fitur Tiktok yang beraneka ragam dapat menonjolkan efek visual dari sebuah produk kepada masyarakat menjadi lebih menarik.

Selain itu, membangun hubungan baik dengan influencer dapat memberikan pengaruh terhadap penjualan online melalui Tiktok. Menurut Hariyanti dan Wirapraja (2018), influencer adalah seseorang atau figur dalam media sosial yang memiliki jumlah pengikut yang banyak atau signifikan, dan hal yang mereka sampaikan dapat mempengaruhi perilaku dari pengikutnya. Penggunaan influencer sebagai sarana pemasar untuk mempromosikan sebuah produk dengan beriklan langsung kepada target audiens. Peran influencer dapat berupa sebagai, endorser, promoter, dan brand ambassador yang dapat dijumpai dalam berbagai media sosial.

Menurut Kotler and Keller (2012), brand image adalah persepsi dan keyakinan yang dilakukan oleh konsumen, seperti tercermin dalam asosiasi yang terjadi dalam memori konsumen. Brand image dapat dibangun dari persepsi positif yang konsisten dan berjangka panjang. Dalam memperkuat suatu brand image diperlukan pemasaran melalui media sosial, khususnya penggunaan influencer marketing. Teori influencer marketing oleh Nick Hayes (2011) adalah pendekatan yang diperbarui untuk pemasaran dan hubungan masyarakat disamping menargetkan orang-orang yang prospek konsumen dapatkan untuk mendapatkan informasi. Pada 
metode ini, influencer berperan sebagai pengguna suatu merek yang mampu merepresentasikan keunggulan yang dimiliki merek sehingga dapat meningkatkan citra merek produk tersebut. Maka dari penjelasan yang telah dipaparkan, peneliti ingin mengetahui adakah pengaruh Influencer Marketing terhadap Brand Image suatu produk sehingga ini merupakan topik yang menarik untuk dikaji lebih lanjut agar UKM (Usaha Kecil dan Menengah) lainnya dapat bersaing di era pandemi saat ini.

\section{Metode Penelitian}

Dalam penelitian ini, peneliti berusaha menganalisis secara komprehensif influencer marketing terhadap brand image pada Bittersweet by Najla melalui platform Tiktok menggunakan pendekatan kuantitatif dengam teknik metode survei. Metode survei adalah penelitian yang dilakukan dengan menggunakan angket sebagai alat penelitian yang dilakukan pada populasi besar maupun kecil, sehingga ditemukan kejadian relatif, distribusi, dan hubungan antar variabel, sosiologis maupun psikologis (Sugiyono, 2013)

Terhitung hingga akhir September 2020, akun Tiktok Bittersweet by Najla memiliki pengikut sebanyak 751.300 orang. Dalam menentukan sampel, peneliti menggunakan sampel secara acak (simple random sampling). Teknik ini merupakan pengambilan anggota sampel dari populasi dilakukan secara acak tanpa memperhatikan strata yang ada dalam populasi tersebut (Sugiyono, 2013). Perhitungan jumlah sampel menggunakan rumus slovin dengan persentase kelonggaran ketidaktelitian sebesar $10 \%$, sehingga hasil dari pengolahan sampel yang didapatkan adalah 100 orang.

Peneliti mengumpulkan data menggunakan sumber data primer dan sekunder. Sumber data primer diperoleh melalui kuesioner yang disebarkan secara acak melalui media Tiktok kepada 100 responden yaitu pengikut dari Bittersweet by Najla. Kemudian peneliti juga menggunakan studi kepustakaan sebagai sumber data sekunder dengan menelaah jurnal, buku, karya ilmiah, penelitian terdahulu serta web browsing untuk memperoleh informasi yang berhubungan dengan variabel yang diteliti yaitu influencer marketing dan brand image.

\section{Hasil Penemuan dan Diskusi}

\section{Karakteristik Responden}

Berdasarkan hasil kuesioner yang disebarkan kepada pengikut Bittersweet by Najla melalui platform Tiktok, penulis memperoleh data karakteristik responden yang terdiri dari jenis kelamin, umur, dan durasi responden menggunakan platform Tiktok. Jumlah karakteristik responden berdasarkan jenis kelamin sebanyak 76 orang (76\%) dan responden yang berjenis kelamin laki-laki sebanyak 24 orang (24\%). Kemudian, sebagian usia responden $<17$ tahun sebanyak 3 orang (3\%), usia responden 17-27 tahun sebanyak 94 orang (94\%), dan usia responden $>27$ tahun sebanyak 3 orang (3\%). Hal ini menunjukkan bahwa dominasi umur followers Bittersweet by najla di meda Tiktok diantara 17 sampai dengan 27 tahun. Berdasarkan kategori durasi responden menggunakan Tiktok yaitu dari 100 responden yang menjadi followers Bittersweet by Najla melalui Tiktok sebagian menggunakan platform ini selama $<1$ jam sebanyak 64 responden (64\%), selama 1-3 jam sebanyak 32 responden $(32 \%)$, dan untuk durasi $<3$ jam hanya 4 responden 
Winnie Agustina, Wulan Purnama Sari: Pengaruh Influencer Marketing Tiktok terhadap Brand Image Bittersweet by Najla

(4\%). Hal ini menunjukkan bahwa sebagian besar responden menggunakan platform Tiktok selama kurang dari 1 jam.

\section{Analisis Deskriptif}

Berdasarkan hasil analisis deskriptif yang dilakukan peneliti menunjukkan bahwa dalam variabel influencer marketing (X) memiliki nilai rata-rata (mean) tertinggi, yaitu sebesar 4,29 yang terdapat pada pernyataan butir ke-7, yaitu "Saya merasa bahwa influencer yang memiliki banyak pengalaman di bidang kuliner dapat membangun citra Bittersweet by Najla di platform Tiktok semakin efektif." Pernyataan ini berada pada dimensi expertise (keahlian) dengan indikator pengalaman. Dimensi expertise mengacu pada pengalaman dan keahlian yang dimiliki oleh seseorang dengan merek yang didukung.

Sedangkan hasil analisis deskriptif yang didapat pada variabel brand image (Y) memiliki nilai rata-rata (mean) tertinggi sebesar 3,97 yang terletak pada penyataan butir ke-2 dan ke-4, yaitu "Saya merasa bahwa Bittersweet by Najla telah memiliki banyak penggemar yang menyukai produknya melalui platform Tiktok" dan "Bittersweet by Najla telah membuka banyak cabang hampir di Indonesia, sehingga telah menciptakan reputasi yang baik khususnya melalui platform Tiktok". Pada pernyataan Y2 berada pada dimensi recognition (pengakuan) dan pernyataan Y4 terletak pada dimensi reputation (reputasi).

\section{Analisis Regresi Linear Sederhana}

Tabel 1. Analisis Regresi Sederhana

\begin{tabular}{|c|c|c|c|c|c|c|}
\hline \multicolumn{7}{|c|}{ Coefficients $^{\mathrm{a}}$} \\
\hline & \multirow[b]{2}{*}{ Model } & \multicolumn{2}{|c|}{$\begin{array}{l}\text { Unstandardized } \\
\text { Coefficients }\end{array}$} & \multicolumn{3}{|l|}{$\begin{array}{c}\text { Standardized } \\
\text { Coefficients }\end{array}$} \\
\hline & & $\mathrm{B}$ & Std. Error & Beta & $\mathrm{t}$ & Sig. \\
\hline 1 & (Constant) & 1.055 & 1.998 & & .528 & .599 \\
\hline & $\begin{array}{l}\text { Influencer } \\
\text { Marketing }\end{array}$ & .472 & .033 & .823 & 14.342 & .000 \\
\hline
\end{tabular}

Sumber: Hasil Olah Data SPSS 25

Berdasarkan tabel di atas, diperoleh nilai a sebesar 1,055 dan koefisien $b$ sebesar 0,472 yang dapat diinterpretasikan yaitu, a sebagai angka konstan dari unstandardized Coefficients. Angka ini merupakan angka konstan yang mempunyai arti bahwa jika tidak ada Influencer Marketing (X) maka nilai Brand Image (Y) adalah 0,472. Sedangkan $b$ adalah koefisien regresi bernilai sebesar 0,472. Angka ini mengandung arti bahwa setiap penambahan 1\% tingkat Influencer Marketing (X), maka Brand Image (Y) akan meningkat 0,472. Koefisien regresi tersebut bernilai positif, artinya terjadi hubungan positif antara Influencer Marketing terhadap Brand Image Bittersweet by Najla.

\section{Pembahasan}

Dari hasil penelitian ini diperoleh bahwa influencer marketing dalam kelima indikatornya memberikan pengaruh yang signifikan terhadap brand image, khususnya indikator expertise. Hal ini dibuktikan oleh peneliti melalui analisis deskriptif terhadap variabel influencer marketing dengan hasil mean tertinggi pada 
pernyataan yang berada pada indikator expertise. Peneliti juga melakukan uji hipotesis dengan menggunakan uji $\mathrm{t}$ untuk membuktikan ada atau tidak adanya pengaruh pada penelitian ini. Pada hasil uji hipotesis ini menghasilkan perhitungan sebesar $t_{\text {hitung }}(14,342)$ dan $t_{\text {tabel }}(1,984)$, sehingga dapat dilihat bahwa $t_{\text {hitung }}$ lebih besar daripada $t_{\text {tabel }}$ dan terbukti memberikan pengaruh terhadap variabel.

Dengan memahami aspek tersebut dengan baik maka pemasaran iklan melalui platform Tiktok dapat menambah nilai jual dari produk Bittersweet secara efektif. Media penyebaran yang digunakan oleh Bittersweet by Najla yaitu Tiktok dalam menyebarkan iklan tersebut cukup efektif dalam menjangkau masyarakat. Di era teknologi yang semakin berkembang, Bittersweet mampu berdaptasi dengan perkembangan media secara baik, terutama Tiktok menjadi media yang paling banyak diunduh per Juli 2020 dan sebagian besar dikonsumsi oleh generasi Z yang merupakan target pasar Bittersweet. Dengan adanya penggunaan influencer marketing ini, konsumen lebih mengetahui keberadaan dan kualitas Bittersweet, sehingga meningkatkan brand image dan membentuk status yang cukup tinggi di kalangan masyarakat.

Kepercayaan dan loyalitas masyarakat terhadap Bittersweet pun juga ikut meningkat karena menggunakan influencer yang tepat dan memiliki citra yang baik. Konsumen juga memiliki rasa emotional relationship yang tumbuh karena mereka menyukai Bittersweet yang dipengaruhi oleh influencer yang dianggap memiliki keahlian dan kepercayaan yang tertanam dibenak konsumen sehingga loyalitas konsumen meningkat. Selain itu, tingkat recognition dari konsumen juga meningkat karena mereka mampu mengingat produk Bittersweet dengan baik dari segi kemasan maupun rasa. Reputation Bittersweet juga memiliki suatu track record yang baik dimata konsumen karena Bittersweet merupakan pelopor dessert box no.1 di Indonesia sehingga ini menjadi suatu peluang yang besar oleh Bittersweet untuk meningkatkan citra mereka.

Walaupun tidak semua konsumen memiliki pendapat yang sama mengenai influencer marketing terhadap Bittersweet, namun pendapat mereka memiliki nilai yang sebagian besar sama. Dilihat dari banyaknya pengaruh seperti pengaruh emosi, kesamaan terhadap influencer, kepercayaan, dan dinilai dari pengalaman serta beberapa pemahaman responden terhadap iklan tertentu sehingga hal ini akan mempengaruhi persepsi dan pemikiran mereka terhadap citra Bittersweet by Najla.

\section{Simpulan}

Berdasarkan hasil penelitian yang telah dilakukan, peneliti menyimpulkan bahwa influencer marketing berpengaruh terhadap brand image Bittersweet by Najla melalui platform Tiktok. Hal ini dapat terjadi karena pemasaran dilakukan oleh influencer yang tepat dengan memiliki aspek seperti trustworthiness, expertise, attractiveness, respect, dan similarity dalam mempromosikan produk Bittersweet by Najla sehingga kepercayaan dan loyalitas masyarakat terhadap produk semakin meningkat. Influencer marketing merupakan kunci utama untuk meningkatkan citra perusahaan. Melalui penggunaan media sosial seperti Tiktok yang didominasi oleh kaum generasi $\mathrm{Z}$ merupakan cara yang tepat karena generasi ini mudah beradaptasi terhadap perkembangan teknologi, tren yang terjadi, dan mengonsumsi media dalam kesehariannya. Selain itu, jenis kelamin juga dapat menentukan minat konsumen dalam mengonsumsi iklan. 
Diharapkan kepada pelaku bisnis, harus tetap menjaga kepercayaan konsumen dengan membuat konten yang menarik dan promosi penjualan dengan influencer marketing untuk meningkatkan citra pada produk serta membantu konsumen lebih tertarik dalam melakukan pembelian. Pun bagi peneliti selanjutnya, diharapkan dapat menambah faktor yang mempengaruhi brand image dan memperluas faktor-faktor yang akan diteliti dan objek penelitian yang dipilih lebih umum agar topik penelitian lebih menarik dan diketahui oleh semua kalangan sehingga hasil penelitian yang diperoleh menjadi lebih baik.

\section{Ucapan Terima Kasih}

Peneliti mengucapkan terima kasih yang sebesar-besarnya kepada semua pihak yang membantu terlaksananya penelitian ini hingga dapat dipublikasikan, khususnya dosen dan rekan mahasiswa di Program Sarjana Ilmu Komunikasi Universitas Tarumanagara, serta seluruh responden dan pihak yang sudah mendukung dan berpartisipasi dalam pelaksanaan penelitian ini.

\section{Daftar Pustaka}

Hariyanti, N. T., \& Wirapraja, A. (2018). Pengaruh Influencer Marketing sebagai Strategi Pemasaran Digital Era Modern (Sebuah Studi Literatur). Jurnal Eksekutif, 15(1), 133-146.

Kotler, Philip \& Keller, Kevin. (2013). Manajemen Pemasaran, Jilid Kedua, Edisi 13. Jakarta: Erlangga.

Sugiyono. (2011). Metode Penelitian Administratif. Bandung: Alfabeta.

Sugiyono. (2013). Metode Penelitian Pendidikan Pendekatan Kuantitatif, Kualitatif, dan $R \& D$. Bandung: Alfabeta. 